\title{
Processo de formação e aprendizagens ao longo da vida*
}

\author{
Peter Alheit \\ Université de Göttingen \\ Bettina Dausien \\ Université de Bielefeld
}

\section{Introdução}

0 conceito de "aprendizagem ao longo da vida” permanece maldefinido. Que nós aprendemos durante toda a nossa vida, é evidente. Desde nossos primeiros passos e de nossas primeiras palavras até a nossa idade mais avançada, fazemos experiências novas, adquirimos novos saberes e novas competências. Somos quase tão inconscientes do modo que temos de aprender, quanto do fato de respirarmos. Certamente aprendemos na escola e também na universidade e nos estabelecimentos de formação, mas mesmo nesses lugares instituídos de formação e de aprendizagem, o que aprendemos de verdadeiramente importante, freqüentemente, não tem nada a ver com os programas oficiais. Experimentamos situações, adquirimos habilidades, testamos nossas emoções e nossos sentimentos na "escola" mais efetiva que há: a "universidade da vida" (Field, 2000). Portanto, aprendemos e nos formamos nas conversas com os amigos, assistindo à televisão, lendo livros, folheando catálogos ou navegando na Internet, tanto quanto quando refletimos e quando fazemos projetos. Pouco importa se essa maneira de nos formarmos é trivial ou requintada: não podemos alterar o fato de que somos aprendentes "no longo curso" da vida.

Nos debates dos últimos trinta anos sobre política da formação - particularmente na última década -, o conceito de aprendizagem ao longo da vida tomou uma dimensão estratégica e funcional. É a ele que se recorre para definir as missões de formação das sociedades pós-modernas. 0 mais importante documento europeu so- bre a política de formação, o Memorandum sobre a educação e a formação ao longo da vida, ratificado em março de 2000 em Lisboa, pela Comissão Européia, define: "a aprendizagem ao longo da vida (lifelong learning) não é apenas mais um dos aspectos da educação e da aprendizagem; ela deve se tornar o princípio diretor que garante a todos o acesso às ofertas de educação e de formação, em uma grande variedade dos contextos de aprendizagem" (Commission of the European Communities, 2000, p. 3).

Duas razões principais são evocadas para justificar essa afirmação:

A Europa tornou-se uma sociedade fundamentada no conhecimento e na economia. Mais do que em tempos passados, o acesso às informações e aos conhecimentos mais recentes, assim como a motivação e os saberes necessários à utilização inteligente, pessoal e coletiva desses recursos tornaram-se a chave da competitividade européia, além de serem igualmente benéficos à empregabilidade e à adaptabilidade da força de trabalho;

Os europeus vivem, atualmente, em um mundo social e político complexo. Os indivíduos, muito mais do que antes, querem planejar suas vidas, esperam contribuir ativamente para a sociedade e devem aprender a viver positivamente na sua diversidade cultural, étnica e lingüistica. A educação, no seu sentido mais amplo, é a chave para aprender e compreender como superar es-

* Traduzido por Teresa Van Acker, a partir da versão francesa de Christine Delory-Momberger «Processus de formation et apprentissages tout au long de la vie», publicada em Orientation Scolaire et Professionnelle, 2005, n.1. 
ses desafios. (Commission of the European Communities, 2000, p. 5)

Essa dupla motivação, ainda que restrinja o conceito apenas à dimensão funcional, permite contudo precisar sua definição. $0 \mathrm{Memo-}$ randum estipula claramente que a educação ao longo da vida concerne a todas as atividades significativas de aprendizagem, tais como:

Processos de aprendizagem formais que ocorrem nas instituições de formação clássicas e que são, geralmente, validados por certificações socialmente reconhecidas;

processos de aprendizagem não formais que se desenvolvem habitualmente fora dos estabelecimentos de formação institucionalizados - nos locais de trabalho, em organismos e associações, no seio de atividades sociais, na busca por interesses esportivos ou artísticos;

processos de aprendizagem informais, que não são empreendidos intencionalmente e que "acompanham" incidentalmente a vida cotidiana. (Commission of the European Communities, 2000, p. 8)

0 interesse dessa nova compreensão do conceito de educação reside em estabelecer a sinergia desses diferentes modos de aprendizagem. A aprendizagem não deve ser somente, e sistematicamente, ampliada para toda a duração da vida. Ela deve também se desenvolver "lifewide", quer dizer, generalizar-se para todos os domínios da vida, para isso estabelecem-se, portanto, ambientes de aprendizagem nos quais os diferentes modos de aprendizagem encontram-se para complementarem-se organicamente.

A dimensão do 'lifewide learning' (educação abarcando todos os aspectos da vida) enfatiza a complementaridade entre aprendizagens formais, não formais e informais. (Commission of the European Communities, 2000, p. 9)

Entendida desse modo, a educação ao longo da vida parece responder no primeiro pla- no a uma necessidade econômica e social. Ela não diz respeito apenas a elites tradicionais, mas a todos os membros da sociedade. $O$ Livro branco da educação ao longo da vida, publicado pelo ministério da educação inglês em 1998, afirma em sua proposta central:

Para fazer face à mudança rápida e ao desafio da era da informação e da comunicação, devemos garantir que as pessoas possam voltar a aprender ao longo de suas vidas. Nós não podemos contar com uma pequena elite apenas, qualquer que seja seu grau de educação. Ao contrário, necessitamos de criatividade, de espírito empreendedor e da instrução de todos. (Department for Education and Employement, 1998, p. 7).

0 "conceito novo" de educação ao longo da vida é revelador de um fenômeno societário que o pesquisador em ciências da educação John Field (2000, p. 133) chamou de "nova ordem educativa”. Aprender ganha um significado novo para a sociedade inteira, para as instituições educativas e para os indivíduos. Essa reconfiguração não deixa de ter uma contradição interna: a nova aprendizagem primeiramente inscreve-se em um quadro econômico e político cujos objetivos são a competitividade, a empregabilidade e a adaptabilidade das "forças de trabalho". Ao mesmo tempo, a liberdade biográfica de planejamento e de engajamento social dos indivíduos devem sair, dessa situação, reforçados. A educação ao longo da vida pode aparecer sob o duplo aspecto da "instrumentalização" e da "emancipação".

As reflexões a seguir visam à elaboração dessa tensão. Procederemos inicialmente à elucidação do conceito que nos parece necessário à discussão. Em seguida, faremos uma análise crítica das condições do quadro social da educação ao longo da vida. Depois apresentaremos o conceito de aprendizagem biográfica que representa nossa contribuição teórica à questão da "formação ao longo da vida". Finalmente, consideraremos as perspectivas de pesquisa abertas por esse novo conceito. Nas nossas reflexões, adotamos conscientemente uma 
perspectiva internacional. A educação ao longo da vida relaciona-se claramente com as "contingências da mundialização" das políticas de educação e de formação que deverão ser consideradas na nossa argumentação.

\section{Conceitos e perspectivas}

Em razão dos múltiplos sentidos ligados aos conceitos de educação e de formação ao longo da vida, um breve esclarecimento das noções nos parece útil. Isso nos permitirá, ao mesmo tempo, precisar o ponto de vista que adotamos para essa análise.

\section{“Formação" e “aprendizagem”}

Os conceitos de formação e de aprendizagem, que têm cada um seu campo semântico e sua tradição teórica, não podem ser discutidos sistematicamente e delimitados um pelo outro. $\mathrm{Na}$ seqüência deste texto, eles serão empregados, um e outro, e sua significação será especificada em função do contexto. Globalmente, pode-se diferenciar o conceito mais "restrito" de aprendizagem que se refere à atividade individual e coletiva concreta, do conceito mais amplo de formação, que tende geralmente a indicar os processos de formação individuais e coletivos relacionados acima e as figuras biográficas que permitem a perlaboração da experiência. Quando, no texto que se segue, tratar-se de "aprendizagem", não se referirá aos procedimentos de aquisição e de apropriação progressiva de saberes ou de competências que se procura alcançar, mas ao processo altamente organizado da perlaboração, da ligação e da (trans)formação dos primeiros processos de aprendizagem em uma figura biográfica de experiências, ou seja, de algum modo uma "segunda ordem" de processos de aprendizagem.

\section{“Toda a vida", "ao longo da vida", "biografia"}

A expressão "aprendizagem e formação ao longo da vida" indica, em primeiro lugar, uma medida de tempo, uma expressão quantitativa ou uma duração que é a do tempo de uma vida humana. Em uma primeira abordagem, isso pode parecer trivial, porém a dimensão do tempo ("aprender requer tempo") e a ordem na qual se encadeiam os fenômenos ("uma coisa depois da outra”, "o que não se aprende em pequeno, não se aprende jamais") desempenham sempre um papel importante nos processos de aprendizagem e de formação. De resto, a impressão de trivialidade desaparece quando se trata de definir a maneira pela qual esse aspecto da temporalidade é conceitualizado.

A temporalidade dos processos de aprendizagem não deve ser, necessariamente, pensada na perspectiva do curso integral da vida. A maior parte das teorias (psicológicas) da aprendizagem tematizam, por exemplo, a aprendizagem em termos de mudanças comportamentais - mais ou menos complexas - sobre o horizonte temporal da situação de aprendizagem ou da ação. Uma outra teoria, menos representada nos contextos pedagógicos, questiona os processos de aprendizagem das configurações sociais (instituições, classes, nações, sociedades) em uma dimensão histórica (palavras-chave: história das mentalidades, "herança social", experiências coletivas diante das crises e das mudanças históricas). 0 ponto de vista do "curso da vida" adota um nível de análise temporal específico, que relaciona com outras dimensões temporais, e salienta uma lógica de construção que lhe é própria (Schüller, 1997). Não se trata, nesse caso, da medida quantitativa da "duração da vida" e sim do aspecto qualitativo dos processos que ocorrem toda a vida e de sua estruturação sociocultural. É esse aspecto que é conceitualizado sob o termo de biografia. Apenas uma concepção teórica da biografia - essa será nossa tese - justifica a exposição analítica e a delimitação de "aprendizagem ao longo da vida" (ou ainda aprendizagem "biográfica”) como ob-

1. A duração da vida (Lebenspanne) está certa e biologicamente fundada (por meio de sua relação principal) com a 'hora biológica', porém não está determinada na sua forma social concreta e no individualmente vivido. Nesse sentido, ela é um fenômeno social que, em contextos históricos e culturais específicos, toma a "forma de biografia" (Nassehi, 1994). 
jeto da pesquisa biográfica² (Alheit; Dausien, 2000b; Dausien, 2001).

As reflexões seguintes têm por objeto desenvolver os motivos que fundamentam esse ponto de vista e de indicar as linhas do vasto programa de pesquisa, tanto teóricas quanto empíricas, ao qual ele se abre. 0 caráter programático desse texto decorre do estado atual da pesquisa: apesar da avalanche de publicações (nem sempre completamente) científicas sobre o tema da "educação ao longo da vida", existe ainda, relativamente, poucas reflexões teóricas e, menos ainda, pesquisas empíricas que estudam o fenômeno em si mesmo, sem pressupor abstratamente o contexto.

\section{Um duplo ponto de vista}

A educação ao longo da vida pode ser considerada sob diferentes aspectos. Na discussão atual, distinguem-se acima de tudo dois pontos de vista:

1. Um interesse principalmente motivado pela política da formação vinculado à mudança das condições da sociedade do trabalho e da educação, acarretando conseqüências para a organização social individual e coletiva da aprendizagem (Longworth; Davies, 1999; Dohmen, 1996; Brödel, 1998; Alheit; Kammler, 1998; Gerlach, 2000; Field, 2000; Achtenhagen; Lempert, 2000);

2. Um ponto de vista de caráter essencialmente pedagógico concernente a condições e possibilidades de uma aprendizagem biográfica dos membros da sociedade (Dominicé, 1990; Kade; Seitter, 1996; Alheit, 1999; Alheit; Dausien, 1996; 2000b; Delory-Momberger, [2000] 2004).

0 primeiro ponto de vista inspira, a partir dos anos de 1960, uma política internacional de "educação ao longo da vida" (Dohmen, 1996; Gerlach, 2000; Field, 2000) que visa a pesquisa e o desenvolvimento de novas concepções de formação diante da criação de re- cursos econômicos e culturais relacionados com as sociedades ocidentais. Como pano de fundo, há o diagnóstico de que a mudança social acelerada, as rupturas e as mutações trazidas por ela exigem, para serem superadas pelos atores sociais, competências e flexibilidade que não podem ser adquiridas no ritmo e nas formas institucionalizadas dos processos "tradicionais" de formação. Os limites dos programas de formação devem ser transformados, novas redes sociais e novos ambientes de formação devem ser criados (Alheit, 1999; Field, 2000). As reflexões de natureza política dirigidas a esse contexto assumem, geralmente, a forma de "linhas diretrizes" (Dohmen, 1996) e de memorandos (Field, 2000). Sob esse ângulo, os conceitos e os resultados científicos que poderiam ser pertinentes no contexto da pesquisa em educação serão evocados de forma ampla mais além.

O segundo ponto de vista - que se inscreve no contexto de uma ciência da educação orientada para o sujeito - toma como objeto os processos de aprendizagem e de formação do ator social individual. Nesse contexto, a atenção é focada, principalmente, sobre os aspectos não formais, informais, não institucionalizados e auto-organizados da aprendizagem. As palavras-chave "aprendizagem do cotidiano", "aprendizagem a partir das experiências”, "aprendizagem por assimilação", "aprendizagem ligada ao mundo da vida" ou "autodidaxia" constituem novos temas e campos da pesquisa (Dohmen, 1996; Kade; Seitter, 1996; Ação combinadas formação contínua, 1998). Trataremos dos aspectos desse debate heterogêneo do ponto de vista teórico, sob a perspectiva de uma teoria biográfica e formularemos as conseqüências para a pesquisa na formação ou em formação.

\footnotetext{
2. (Nota de tradução de Delory-Momberger para a tradução francesa) A Biographieforschung ou pesquisa biográficaé um setor das ciências sociais não identificado como tal na França, porém na Alemanha é bem representado, assim como nos países anglo-saxônicos (Biography research) - cujo objeto é estudar as relações entre os fatos sociais e as construções individuais, mostrando, especialmente, como as construções biográficas individuais perlaboram os dados históricos e socioestruturais das experiências e da ação.
} 
Perspectiva 1: "A aprendizagem ao longo da vida" - uma nova ordem educativa

0 consenso político global, que se fecha no final do século XX em torno do conceito de educação ao longo da vida (Field, 2000), constitui um fenômeno surpreendente que exige explicação. Os debates dos anos de 1970, particularmente o relatório da comissão da UNESCO dirigida pelo antigo primeiro ministro e ministro da educação Edgar Faure (1972), assim como uma série de publicações da Organização para a Cooperação Econômica e o Desenvolvimento (OCDE; CERI, 1973), provocaram modestas iniciativas em matéria de política de formação por parte dos governos nacionais (Gerlach, 2000); ao contrário, um documento dos anos de 1990 com o aval de Jacques Delors, o White Paper on Competitiveness and Economic Growth (Commission of the European Communities, 1994), e depois, de forma indubitável, o relatório de uma comissão de especialistas da UNESCO, igualmente sob a responsabilidade de Jacques Delors (1996), conduziram a uma multiplicação de iniciativas internacionais relacionadas com o tema da educação ao longo da vida.

Desde que a Comissão Européia fez de 1996 o ano da educação ao longo da vida (Year of Lifelong Learning), um ministro da "educação ao longo da vida" foi nomeado na Inglaterra; livros verdes e livros brancos sobre os novos objetivos dos sistemas de formação apareceram no País de Gales, na Escócia, na Inglaterra, um pouco mais tarde, também, nos Países Baixos, na Noruega, na Finlândia e na Irlanda; o ministério alemão para a formação, a ciência, a pesquisa e a tecnologia apoiou muitos relatórios e encontros de especialistas sobre o tema (Dohmen, 1996, 1998); a Comissão Européia publicou o Livro branco da educação e da aprendizagem (Commission of the European Communities, 1995); a UNESCO (Delors, 1996), a OCDE (1996) e o grupo dos oito países mais industrializados (Group of eight, 1999) também contribuíram para essa reflexão.
Quatro características de desenvolvimento atuaram de maneira decisiva nessa mudança de paradigma das programações de formação e seus efeitos se associaram para conduzir, nas sociedades pós-industriais ocidentais do final do século XX, ao que John Field chamou de "explosão silenciosa” ("silent explosion") (Field, 2000, p. 35): (a) a transformação da significação do "trabalho"; (b) perturbações intervieram na função do "saber"; (c) a experiência de disfuncionamentos crescentes das instituições de formação; e (d) os desafios dirigidos aos atores sociais, indicados no momento por termos como "individualização", "modernização reflexiva” (Beck, 1986; Giddens, 1990; Beck; Giddens; Lasch, 1996).

\section{A transformação do "trabalho" nas sociedades pós-modernas}

A significação do trabalho produtivo foi profundamente modificada ao longo do século XX. A maior parte das pessoas, certamente, passa menos tempo no trabalho do que seus avós. Em 1906, um ano médio de trabalho correspondia a aproximadamente 2900 horas; em 1946, já não passava de 2440 horas; e em 1988, de 1800 horas (Hall, 1999). A "estrutura interna" do trabalho também mudou. A conversão em massa de empregos do setor industrial para o setor de serviços não passa, nesse sentido, de um indicador superficial. Mais decisivo é o fato de que o valor ligado à representação de "uma vida de trabalho", mesmo se tradicionalmente as mulheres estavam dela excluídas, pertence definitivamente ao passado. Do ponto de vista estatístico, a atividade profissional não remete mais a um único exercício profissional nem ao exercício de um mesmo ofício por um período importante da vida e sim à alternância das fases de trabalho e de fases de formação, de rupturas voluntárias ou involuntárias de trabalho, de estratégias de conduta de carreira e até à alternância de fases de trabalho e de períodos consagrados à família (Arthur; Inkson; Pringle, 1999).

Essa evolução não afetou apenas as representações tradicionais do curso da vida 
(Kohli, 1985; 1989), ela tornou mais arriscados os projetos individuais de vida (Heinz, 2000b) e também trouxe novos problemas às instituições em questão que são "fornecedoras de estrutura do curso da vida" (Heinz, 2000a, p. 5): agências do sistema de emprego e do mercado de trabalho, da segurança social e das aposentadorias, antes de mais nada, instituições do sistema de formação. Algumas delas impuseram-se o desafio de compensar os efeitos da desregulamentação e da flexibilidade do mercado de trabalho, de acompanhar as "mudanças de estatuto" imprevistas e difíceis, de acomodar as transições para modos modernizados de "percursos de vida" e de encontrar um novo equilíbrio entre as opiniões dos atores individuais e as limitações funcionais das instituições (Heinz, 2000a). "A aprendizagem ao longo da vida" apresenta-se, aqui, precisamente como um instrumento de governança inovando as políticas novas do "curso da vida".

\section{A nova função do saber}

Essa idéia de governança mostra-se tão mais necessária quanto o domínio no qual ela se realiza e foge cada vez mais a uma definição. 0 lugar comum, segundo o qual o saber, após as inovações tecnológicas da "sociedade de informação" pós-industrial, tornou-se o principal recurso do futuro, dissimula o embaraço no qual nos encontramos para definir a função e a natureza desse saber (Rahmstorf, 1999). Declaradamente a dificuldade não reside na definição dos objetos do saber que deveriam ser divulgados e partilhados nem na constatação da "cientifização" crescente de todos os domínios da vida (Wingens, 1998; Stehr, 2000), porém na exata apreensão de um fenômeno que se ampliou na mesma medida de seu usos concretos ao se desvalorizar. 0 "saber" não é mais esse "capital cultural" que Bourdieu definiu em função das estruturas sociais e que assegura sua perenidade por meio de processos indefinidamente repetidos da reprodução (Bourdieu, 1987). "Saber" é uma espécie de "capital cerebral” (Field, 2000, p. 1), que produz economias novas e, ao mesmo tempo, virtuais. A crise da bolsa da "nova economia" dos anos de 2000 representa apenas a face sombria desse aspecto de difícil apreensão do "novo saber".

As redes de comunicação e de interação da era da tecnologia informática, que há muito tempo têm penetrado, ampliado e transformado os processos da produção industrial convencional e transtornado as características tradicionais dos serviços e da administração, permanecem, no entanto, mais fortemente dependentes do usuário individual do que as formas de saberes do passado. Os procedimentos personalizados que este desenvolve nos novos mercados virtuais, seus contatos, suas iniciativas, seus hábitos de consumidor na Internet, esboçam já as formas de saberes do futuro. 0 "saber" da sociedade de informação é um doing knowledge, uma maneira de "dar uma forma à vida" que, bem além do domínio profissional, define as estruturas novas da sociedade e as dinamiza em ciclos sempre mais rápidos. As características do "novo saber" exigem, agora, procedimentos flexíveis de feedback, controles complexos de autogovernança e um permanente management da qualidade (Rahmstorf, 1999). Nesse quadro, a finalidade da formação e da aprendizagem transformou-se espetacularmente (Nolda, 1996). Ela não consiste mais em pôr à disposição nem em transmitir saberes, valores ou competências preestabelecidos, porém em permitir, de algum modo, a "osmose dos saberes", sob a forma de trocas permanentes da produção individual e da gestão organizada do saber. A idéia de "aprendizagem ao longo da vida", especialmente, de "aprendizagem autogerida”, parece - ao menos como quadro conceitual - ser particularmente adaptada para acompanhar esse processo.

\section{A disfuncionalidade das instituições de formação}

São precisamente essas condições de uma "sociedade do saber" nascente que põem 
em questão a organização clássica dos dispositivos de ensino e de aprendizagem e as concepções que lhes são subjacentes. Entre essas, é preciso voltar a uma idéia que acompanhou o primeiro momento do rótulo "educação ao longo da vida" no início dos anos de 1970: a teoria do capital humano. Esse conceito "mede" por assim dizer o capital de formação, comparando-o à duração total da escolarização/formação e postula que o alongamento dessa duração tem efeitos positivos sobre a capacidade de aprender ao longo de toda a vida, sobre um ponto de vista crítico (Schüller, 1993; Field, 2000). Uma série de estudos empíricos recentes, conduzidos particularmente na Grã-Bretanha (Tavistock Institute, 1999; Merrill 1999; Schüller; Field, 1999), mostra exatamente o contrário: um simples prolongamento da escolaridade de base sem transformação profunda das condições e da qualidade do processo de aprendizagem conduz, na maior parte das pessoas atingidas, à perda de motivação e a um ajustamento instrumental da aprendizagem, que não favorecem, em nenhum caso, a responsabilização das pessoas pela busca das aprendizagens nas fases ulteriores de suas vidas, ao contrário, tende a desviarem-nas disso (Schüller; Field, 1999).

A nova compreensão da aprendizagem ao longo da vida demanda uma mudança de paradigma na organização da aprendizagem - não apenas na idade adulta, mas desde as primeiras formas da escolaridade. Os fatores que devem orientar a ação educativa não são mais, há muito tempo, o caráter operatório do ensino, a eficácia das estratégias didáticas e o conteúdo dos currículos formais, massa situação e as condições dos aprendentes (Bentley, 1998) e a consideração de seus ambientes de aprendizagem não formal e informal. A questão central da pedagogia não é mais saber como uma determinada matéria pode ser ensinada da maneira mais eficaz possível, porém quais são os ambientes de aprendizagem que são os melhores para estimular a responsabilização dos processos de aprendizagem pelos próprios aprendentes, ou seja, como o aprender pode ser “aprendido" (Simons, 1992; Smith, 1992).
Seguramente essa perspectiva inclui a transmissão de competências de base como a leitura, a escrita, o cálculo ou a utilização autônoma do computador, porém, até mesmo essas basic skills devem estar ligadas a experiências práticas e as habilidades cognitivas adquiridas devem ser relacionadas a competências sociais ou afetivas (Giddens, 1998). A adição de tais escolhas pedagógicas demanda das instituições educativas um alto grau de reflexividade sobre si mesmas. Elas devem aceitar, por sua vez, colocarem-se a si mesmas "em aprendizagem”. A necessidade de preparar seus usuários para responsabilizarem-se pelos processos de aprendizagem que deverão conduzir ao longo da vida pressupõe, efetivamente, a idéia de uma lifewide learning, de uma "aprendizagem abarcando todos os aspectos da vida".

As escolas devem estar relacionadas com o bairro ao qual elas estão instaladas, com as empresas, as associações, as igrejas, os sindicatos que ali desenvolvem suas atividades, com as famílias dos alunos que elas acolhem. Elas devem imaginar novos lugares onde aprender e inventar outros ambientes de aprendizagem. Novas concepções do desenvolvimento da escola, passando especialmente pela autonomia progressiva dos estabelecimentos, deveriam abrir indubitavelmente novas possibilidades. 0 que vale para a escola vale, naturalmente, também para as universidades e para o conjunto dos estabelecimentos de ensino. A aprendizagem ao longo da vida requer, seguramente, segundo as palavras de John Field (2000, p. 133), "the new educational order" ou, se preferirmos, uma "revolução silenciosa" da educação.

\section{“Individualização” e "modernização reflexiva"}

Essa reivindicação nada tem de absurdo nem de utópico se se considerar a situação de um número crescente de membros da sociedade. As exigências dirigidas aos indivíduos na segunda metade do século XX mudaram. Os fatores econômicos participaram dessa mudan- 
ça, mas não são exclusivos. Outros fatores como os processos de transformação sociais e culturais tiveram também um papel determinante. Apesar do crescimento das desigualdades sociais, os laços entre os meios sociais e as mentalidades tradicionais se desataram (Beck, 1983; 1986; Vester et al., 1993; Alheit, 1994). Os modelos de conduta individual se inscrevem em um espaço mais restrito e se referem prioritariamente às experiências da mesma geração ou do mesmo sexo, à certa percepção da identidade étnica ou até à preferência por certos estilos de vida (Alheit, 1999). A inflação da oferta informativa e de associações de consumidores tem aumentado espetacularmente as possibilidades de escolha dos atores sociais (Giddens, 1990; Shulze, 1993a). 0 desenvolvimento das trajetórias de vida é, conseqüentemente, muito menos previsível hoje do que em épocas passadas. E mais do que isso: a pressão para tomar decisões sempre novas, para mudar continuamente de orientação, é interiorizada de maneira mais ou menos clara pelos próprios indivíduos.

Os indivíduos são dependentes em um grau elevado das instituições e dos meios que outros e não eles próprios dispõem; no entanto, como atores, eles são levados a produzir por si mesmos a coerência e a unidade de suas vidas por meio dos recursos próprios de suas ações [...]. Eles devem aprender, sob pena da ruptura de sua personalidade ou de um prejuizo social permanente, a relacionar por si mesmos diferentes campos de experiência e de ação [...]. Eles também devem saber equilibrar por si mesmos as solicitações e as exigências aparentemente incompativeis dos espaços sociais, de instituições e domínios da vida múltiplos e contraditórios entre si, ainda que seja apenas para poder viver no cotidiano. Os imperativos da integração social reforçam ainda essa tendência: é aos indivíduos como tais, e não mais aos grupos sociais primários, que cabe a tarefa de relacionar e coordenar suas ações e aquilo que eles pretendem de suas vidas. [...] Ou os indivíduos, por si mesmos, criam socialidade ou estão ameaçados de afastamento e isolamento social. (Körber, 1989, p. 139)

A amplitude ainda não mensurável dessa tendência à "individualização" das trajetórias de vida e a obrigatoriedade resultante de uma contínua "reflexividade" do indivíduo sobre suas próprias ações conduziram, para retomar as teses de Ulrich Beck e Anthony Giddens, a uma outra forma de modernidade, à "modernidade reflexiva” (Beck; Giddens; Lasch, 1996). 0 vínculo com essa outra modernidade (Beck, 1986) requer competências novas, "flexiveis", que só podem ser construídas e desenvolvidas nos processos de aprendizagem conduzidos ao longo da vida (Field, 2000). Apenas uma transformação profunda do sistema de formação é capaz de responder a tal exigência.

\section{Esboço de uma outra "economia da formação"}

Esses diagnósticos sobre nosso tempo, aparentemente aceitos e que, aliás, completamse uns aos outros, são objeto de um consenso que pode surpreender por abarcar desde os representantes da empresa tradicional aos protagonistas da nova economia e aos especialistas da formação dos partidos da esquerda moderna. 0 que instiga a problematizar essa identidade de visões é o desconhecimento que esta revela em relação às conseqüências sociais que provocariam uma transformação sem distanciamento crítico das políticas de formação. 0 rótulo elogioso de Lifelong Learning Society não faz desaparecer, de nenhum modo, os mecanismos de seleção e de exclusão do "antigo" sistema de formação. Ele se contenta em encobri-lo e talvez até o agrave.

Pode-se observar hoje que os segmentos do mercado de trabalho que demandam o mínimo de qualificação diminuem de maneira crônica (OCDE, 1997a). Isso significa que as esperanças da "sociedade do saber" exercem uma pressão mais forte sobre os indivíduos, a 
quem se pede que apresentem padrões determinados de saber e de qualificação. Para aqueles que não se enquadram nas exigências, as conseqüências são mais graves do que na sociedade industrial convencional. Seguramente, a lógica da exclusão repousa sobre os mesmos mecanismos: a classe social e o sexo permanecem como os indicadores determinantes (Field, 2000). Entretanto, a idade, por sua vez, tem um papel cada vez maior (Tuckett; Sargant, 1999). Quem nunca teve a chance de aprender a aprender não fará mais o esforço para conseguir novas qualificações ao longo do desenrolar de sua vida.

Sob o aspecto da estrita avaliação econômica, o cenário futurista da "sociedade de aprendizagem" invoca, talvez, o ceticismo: um pequeno número de "ganhadores" sobre quem pesa, aliás, o veredicto de uma aprendizagem "sem fim" e, diante deles, uma população crescente de "perdedores", que jamais teve a chance de aprender ou que se libertaram voluntariamente da obrigação de adquirir os novos saberes e de deverem pagar o preço disso. As previsões da OCDE não estão muito distantes desse cenário:

Para aqueles cuja experiência de educação é positiva e que se consideram a si mesmos como aprendentes competentes, continuar a aprender é uma experiência enriquecedora que aumenta neles o sentimento de domínio sobre suas próprias vidas e sobre a sociedade. Ao contrário, para os que estão excluídos desse processo ou que escolhem não participar dele, a generalização da educação ao longo de toda a vida só pode ter o efeito de aumentar seu isolamento em relação ao mundo do conhecimento. No plano econômico, as conseqüências disso são o subemprego dos recursos humanos e o crescimento dos encargos da assistência; no plano social, a alienação dos indivíduos e a decomposição da infra-estrutura social. (1997b, p. 1)

Conseqüentemente, seria razoável pensar que a aprendizagem ao longo da vida não representa apenas um investimento em um capital econômico e financeiro a curto prazo, mas também um investimento em um "capital social”, aquele que ativamos nas nossas relações e nossas maneiras de ser com nossos próximos - família, vizinhos, colegas, conhecimentos e as pessoas que encontramos nas nossas atividades associativas e de lazer (Field, 2000). Nesse terreno em que ninguém está excluído e onde todos são "especialistas”, somos todos "aprendentes ao longo da vida". Um encolhimento desse "capital social", a diminuição da "confiança”, o congelamento das "solidariedades" como Robert D. Putnam (2001) constatou há alguns anos, para os Estados Unidos, são a médio prazo economicamente contraprodutivos. Um equilíbrio entre essas duas formas de capital, quase sempre antagonistas, poderia todavia conduzir, nas sociedades da nova modernidade, a uma forma nova de "economia da formação" ou mais justamente, talvez, a uma ecologia social da aprendizagem (Alheit; Krietz, 2000). A condição para isso seria que se considerasse seriamente o indivíduo aprendente, ou seja, que se procedesse a uma mudança de perspectiva.

\section{Perspectiva 2: Processo biográfico de formação - aspectos de uma fenomenologia da aprendizagem ao longo da vida}

As reflexões que seguem têm por objeto os aspectos individuais da aprendizagem ao longo da vida, ou seja, não os atos situados de aprendizagem de indivíduos particulares, mas a aprendizagem como (trans)formação de experiências, de saberes e de estruturas de ação na inscrição histórica e social dos modos-de-vida individuais. Também falaremos de "aprendizagem biográfica” e, mais do que considerar um objeto delimitado de forma empírica - os processos de aprendizagem ligados às formas, aos lugares ou aos tempos determinados -, desenvolveremos, com base em uma concepção fenomenológica da aprendizagem (Schulze, 1993a; 1993b), uma perspectiva teórica, relacionando os processos de 
formação à historicidade vivida da experiência feita pelos aprendentes.

No nível da experiência biográfica, as distinções analíticas entre aprendizagem formal, não formal e informal não são operatórias. A biografia tem precisamente como propriedade integrar, no processo global de empilhamento da experiência vivida, os domínios das experiências que os recortes institucionais e sociais separam e especializam e os (re)unir em uma figura com sentido particular. Essa capacidade de o sujeito perlaborar a experiência vivida pode ser refletida no conceito de biograficidade (Alheit, 1993; Alheit; Dausien, 2000b), que considera a idéia do caráter "obstinadamente" subjetivo da assimilação das ofertas de aprendizagens que, contudo, a elas agrega a possibilidade de elaboração de novas estruturas de experiência culturais e sociais. É a esse potencial de formação contido na lógica da construção biográfica da experiência e da ação que se reúnem - ao menos no nível das intenções declaradas - as políticas e os conceitos pedagógicos do Lifelong Learning.

Todavia a distinção entre aprendizagem formal, não formal e informal também faz sentido na perspectiva biográfica, com a condição de que ela não seja interpretada como tipologia dos processos de aprendizagem, mas que seja relacionada às estruturas e aos quadros dos contextos de aprendizagem que lhes correspondem. Se os processos de aprendizagem como tais só se encontram representados por uma parte ínfima dos lugares instituídos e nas seqüências formalizadas de aprendizagem, as instituições de formação constituem, porém, espaços possíveis de estruturação dos processos de aprendizagem biográfica (Klade; Seitter, 1996) e elas contribuem para modelar as representações das "biografias" no quadro das quais os sujeitos interpretam suas experiências e produzem seu próprio sentido biográfico. A aprendizagem biográfica está ligada às estruturas sociais e aos contextos culturais de significação. É necessário também, para a análise dos processos de aprendizagem e de formação das biografias individuais, explicitar o quadro estrutu- ral "exterior" das trajetórias de vida. É esse o ponto de partida da tentativa de conceitualização que se segue e que desenvolveremos ao descrever de maneira fenomenológica alguns dos aspectos da aprendizagem ao longo da vida.

\section{A estruturação social das trajetórias de vida por meio das instituições de formação}

0 "curso da vida", entendido como instituição ligada à modernidade (Kohli, 1985), oferece um "esqueleto" formal a partir da qual os processos biográficos de formação encontram sua orientação. E isso, em um primeiro momento, independentemente dos traços aparentes que essa orientação assume nos casos concretos (por exemplo, voltada positivamente para a realização de esquemas formais ou, ao contrário, confrontando-se com eles, em ruptura com eles, transformando-os etc.). Existe um "curriculum" social que delimita a vida individual do nascimento até a morte ao estabelecer graus variáveis de leis e sanções, normas e esquemas de espera, objeto de incessantes recomposições e submetido às transformações históricas.

Uma parte dos processos de formação que atravessamos ou que operacionalizamos de forma ativa ao longo de nossa vida está em relação relativamente estreita e imediata com esse "curriculum" e é regulado por objetivos de aprendizagem e certificações de caráter formal. Para designar essa dimensão das aprendizagens, Schulze (1993a) fala de "aprendizagem curricular". Inversamente, a "aprendizagem biográfica" segue outras regras (precisamente biográficas), porém não pode prescindir completamente desse esqueleto formal. As duas faces da aprendizagem estão em uma relação de tensão entre elas e se condicionam mutuamente (Schulze 1993a; Kade; Seitter, 1996).

Para se compreender os processos biográficos de aprendizagem, também é necessário considerar os modelos de trajetórias de vida em vigor em cada sociedade. Seguramente estes não são sempre dados externos, "visíveis a olho nu", 
são modelados de forma determinante por meio de procedimentos de institucionalização da formação. Kohli (1985) descreveu a divisão tradicional do percurso de vida nas sociedades ocidentais modernas segundo três fases: preparação, atividade e repouso. Esse modelo define, mediante a divisão tradicional dos sistemas de ensino (primário, secundário, profissional) e da localização temporal dos processos de socialização e de qualificação na infância e juventude, tempos e espaços de aprendizagem formalizados que devem ser obrigatoriamente transversais a todos os membros da sociedade. 0 papel da formação no percurso de vida não se limita, no entanto, à “fase preparatória”, ele estrutura, sob a forma de um encadeamento de escolhas efetuadas e de direcionamentos, o desenrolar completo do currículo biográfico. Isso também vale para a norma biográfica estabelecida por Kohli para as sociedades modernas: por meio do sistema de formação geral da escola e dos níveis e perfis de qualificação que ele determina, são fixadas as chances de partida e são estabelecidos os pontos de desvio que orientarão o curso da vida vindoura e definirão o posicionamento social dos indivíduos. As formações posteriores terão pouca influência sobre as determinações iniciais (Rabe-Kleberg, 1993b). Ao mesmo tempo, a escola é um lugar central de aproximação metódica aos processos formais de aprendizagem. Aquilo que se aprende na escola, ao mesmo tempo que os conteúdos de saberes, são também formas de aprender. Os níveis de escolaridade seguidos e as experiências escolares estruturam em larga medida as passagens de estatuto posteriores, o acesso à formação profissional e/ou a passagem para a vida ativa e modelam o âmbito da biografia profissional toda. A formação contínua ou os dispositivos de reconversão podem, evidentemente, abrir novas possibilidades: elas permanecem, contudo, sempre dependentes do nível inicial e dos modelos preestabelecidos de percurso e de carreira que diferem consideravelmente, não apenas de um ponto de vista especificamente pro- fissional, mas também segundo critérios do posicionamento social (classe social, sexo, origem étnica, nacionalidade): os ofícios considerados como tipicamente femininos oferecem exemplos significativos dessa disparidade social (Rabe-Kleberg, 1993a; Born, 2000). Por fim, a última grande fase, a idade da aposentadoria, em suas condições estruturais - capital econômico, capital social e também recursos em termos de saúde, de capacidade corporal e disposição de tempo -, é também determinada pela última atividade profissional exercida e se encontra, ao menos indiretamente, dependente da história de formação da pessoa.

Com a transformação da atividade profissional, essa tripartição do percurso de vida, com certeza, deixa de ser pertinente. Entretanto os novos esquemas de percurso de vida, marcados ao mesmo tempo pela tendência à individualização e pela pluralidade dos modelos de referência, não sofrem menos com a dominação crescente das instituições de formação. Estas, por sua vez, devem encontrar sua posição em relação às novas "biografias de aprendizagem ao longo da vida” (Nuissi, 1997). Aliás, as formas de estruturação mudaram: os processos de formação não se sucedem mais de forma absolutamente linear no sentido de uma qualificação ou de um posicionamento social progressivos (o que remete à noção de "carreira"), mas apresentam formas de retomada por ciclos ou por "recomposição de uma trama" no sentido de uma "configuração setorial da existência" (Kade; Seitter, 1996, p. 143).

Independentemente desse primeiro ensaio de diferenciação dos modos de estruturação biográfica da formação, podemos constatar que a formação como instituição social, ou seja, como sistema de instituições interconectadas, modela os tipos estruturais de percurso de vida e condiciona os projetos de vida e as experiências dos sujeitos. A comparação histórica e social permite reconhecer que essa modelação afeta os critérios de diferenciação social - a classe social, o sexo, a origem étnica - e que, estruturalmente, os percursos de vida distribu- 
em de maneira desigual as oportunidades dadas a cada um, padronizadas segundo a posição social. Do ponto de vista das existências individuais, eles representam "modelos para uma vida possivel".

\section{A (des)ordem temporal da formação e da aprendizagem no percurso de vida}

Além do posicionamento no espaço social, a "formação" produz antes de tudo uma ordem de temporalidade dos processos de aprendizagem sobre o eixo das biografias individuais. A situação que conhecemos hoje é a de um conjunto heteróclito no qual estão lado a lado, em parte, o que subsiste das normas do modelo tripartite de formação e de atividade profissional, que evocávamos acima, ao que é preciso integrar o esquema contraditório das "biografias femininas" (Dausien, 1996) e, em parte, os novos modelos marcados pela flexibilidade da aprendizagem ao longo da vida. Particularmente, desde a reforma da formação dos anos de 1960, novas vias de qualificação foram abertas por políticas de formação estabelecidas que permitiram estender os processos de formação à idade adulta. Essas "segunda e terceira via de formação" foram apropriadas por muitos indivíduos adultos (particularmente as mulheres) e não apenas conduziram a uma maior mobilidade da formação (Schlüter, 1993; 1999), mas também criaram novos esquemas de percurso de vida, nos quais o "trabalho", a "família" e a "formação" podem se alternar e se combinar de múltiplas formas. Sem que possamos chegar ao detalhe desses modelos estabelecidos empiricamente, devem ser distinguidos três aspectos relativos à ordem de temporalidade da formação nos percursos de vida, que são típicos das experiências biográficas no contexto de um modo cada vez mais individualizado de conduta da vida:

a) Retomadas e "vieses" de formação: trata-se de uma "segunda (terceira, quarta...) chance" pelo viés de diferentes vias possíveis no interior do sistema de formação e de profissionalização, de recuperar as ocasiões perdidas, ou seja, de corrigir as orientações anteriores. As possibilidades de recuperação são, além do mais, limitadas, dada a impossibilidade de retomar o tempo da vida e de retornar às encruzilhadas de orientação e aos umbrais de progressão nos episódios passados de formação. Os ofícios caracterizados como tipicamente femininos (Rabe-Kleberg, 1993a), freqüentemente descritos como “impasses" profissionais, são um bom exemplo. A realização pessoal que tais "vieses de formação" trazem consigo, em geral, choca-se com as estruturas sociais que, apesar da extensão recente desses modos "flexíveis" de formação, sancionam até aqui de forma ainda majoritariamente negativa as distâncias em relação ao modelo de carreira (masculino) fundado na continuidade profissional (Rabe-Kleberg, 1993b). Na Alemanha, nem o sistema de formação nem o sistema profissional estão prontos a reconhecer e a integrar, em processos individualizados (biográficos) de formação, as qualificações e as competências adquiridas "por contrabando" das instituições, particularmente quando estas forem em ambientes de aprendizagem não formais ou nos casos de biografias de imigração - em outros contextos sociais e nacionais (ver a tradição inglesa do Assessment of Prior Experiential Learning; Alheit; Piening, 1999). Os problemas de ajustamento daí decorrentes devem ficar ao encargo dos próprios indivíduos e podem conduzir de maneira imprevisível a conflitos, rupturas e recusas em relação aos programas instituídos de formação. As margens de liberdade conquistadas com a abertura do sistema de formação escondem, desse modo, novos riscos biográficos (Kade, 1997).

b) Formação contínua e qualificação permanente: constatou-se ao longo dos últimos anos um crescimento evidente da necessidade sentida e/ou do interesse pessoal pela busca da qualificação pessoal (Field, 2000). Os motivos dados são, em geral, a aceleração da mudança tecnológica e a rápida desvalorização que, re- 
centemente, afeta os saberes profissionais. A formação e a qualificação não estão mais confinadas à fase de "preparação" da vida ativa e tornam-se um fator permanente de acompanhamento do percurso profissional. Duas outras transformações sociais contribuem para a crescente importância que se confere à extensão da formação à duração da vida ativa: por um lado, as mutações sociais que chegam no período da "terceira idade" e a mudança de significação biográfica a ela vinculada (Kade, 1994a; 1994b; Mader, 1995), que fazem da "idade pós-profissional" uma fase específica da formação (Kade 1994a); por outro lado, o interesse reforçado que as mulheres manifestam pela formação contínua na vida profissional. Como Shiersmann $(1987,1993)$ mostrou, o campo da formação constitui um dos aspectos da estruturação sexuada da sociedade. As desvantagens e os obstáculos que as mulheres encontram no sistema de formação profissional contínua prolongam o sexismo dos procedimentos de seleção e de hierarquização da formação inicial. A perspectiva crítica abre aqui novos pontos de vista. Para as mulheres, a formação contínua não é de forma alguma o instrumento "neutro" de um plano de carreira, mas se inscreve em um projeto de vida que associa estreitamente a vida profissional às possibilidades e às perspectivas da vida familiar. Essas experiências de reconstituição biográfica dos diferentes campos da vida constituem cada vez mais, até para os homens, uma característica geral da formação contínua.

c) Processos de formação na "temporalidade própria" da vida: além de seus aspectos funcional e estratégico, as retomadas do ciclo de estudos formais e a perenização da qualificação profissional têm, ambas, uma significação pessoal nas biografias individuais. Não se trata apenas - raramente é a primeira razão invocada - do valor exploratório (freqüentemente ignorado) das qualificações visadas no mercado de trabalho, mas de uma compensação dos déficits de formação experimentados ao longo da vida ou, se se preferir, de uma compensação das aspirações de for- mação não satisfeitas. 0 fundamento biográfico de tais motivações de formação conduz a conceber a organização do tempo da existência como uma seqüência de decisões, de transições, de episódios de aprendizagem. A temporalidade própria dos processos de formação pode harmonizar-se às estruturas institucionais por fases e delas se aproveitar, porém, pode tomá-las pelo reverso e até pelo seu contrário. A temporalidade biográfica obedece a uma lógica individual que religa passado, presente e futuro, freqüentemente passando por cima das periodizações institucionais e dos compartimentos sociais entre os campos da vida. Ao contexto da significação das biografias individuais, sucede uma necessidade de formação e de desenvolvimento da personalidade estruturada no tempo que ordena, de forma reflexiva ou como estrutura biográfica implícita aos processos de formação. Daí decorre, sem cessar, novas fases ou novas situações nas quais se solicita essa necessidade de reflexividade, de reconstrução, de sincronização, de projeto da "vida pessoal" e que são tantas ocasiões possiveis de confrontação com programações estabelecidas de formação. Como estudos empíricos conduzidos segundo os métodos da pesquisa biográfica mostraram, os adultos utilizam, muitas vezes, as ofertas de formação contínua, não apenas de modo instrumental para seguir as vias de aprendizagem preestabelecidas, mas também para se propiciar espaços temporais nos quais poderão desenvolver seus próprios processos de aprendizagem e sua capacidade de reflexão sobre si mesmos (por exemplo nos cursos das Volkshochschulen [universidades populares] Alheit; Dausien, 1996; ou no ensino a distância, Kade; Seitter, 1996).

\section{A formação como processo biográfico}

Considerar a estrutura temporal dos processos de aprendizagem nas biografias individuais remete à questão fundamental da forma pela qual a formação pode ser compreendida como processo relativamente autônomo 
diante das trajetórias da vida e dos currículos. A formação não é redutível às suas únicas formas organizadas e institucionalizadas. Ela engloba todo o complexo de experiências vividas cotidianamente, de episódios de transição e de crise. Na dimensão vivida, a aprendizagem está, assim, sempre ligada ao contexto de uma biografia concreta. Por outro lado, é também a condição ou o instrumento de mediação no qual as construções biográficas, como formas reflexivas da experiência, podem se desenvolver e se transformar. Sem biografia, não há aprendizagem; sem aprendizagem, não há biografia:

a) Aprendizagem implícita, reflexão e saber pré-reflexivo: muitos dos processo de aprendizagem se desenvolvem de forma "implícita" e toma a forma de esquemas de experiência e de ação, sem que eles sejam a cada vez refletidos de forma explícita. Conceitos como aprendizagem implícita, aprendizagem esporádica salientam esse aspecto, mas não informam nada sobre a complexidade desse fenômeno na dialética do ajustamento ao mundo e da formação de si. Mediante os processos de aprendizagem implícita que se desenvolvem desde o início da vida tanto no interior como no exterior das instituições, não são apenas os elementos singulares da experiência que são assimilados como componentes do mundo social, é também o próprio "sistema de assimilação" que se desenvolve. Trata-se aqui da formação de estruturas superordenadas e geradoras da ação e do saber que, segundo as opções teóricas, podem ser interpretadas como estruturas de aquisição e de desenvolvimento das "disposições de aprendizagem" (Field, 2000), estruturas cognitivas no sentido de Piaget, "sistema emocional de orientação" (Mader, 1997), formação de habitus (Bourdieu, 1987) ou construção do sistema de referências de si e do mundo (Marotzki, 1990). 0 conjunto desses processos, segundo os quais se constrói a experiência, forma a "reserva de saberes biográficos" de uma pessoa (Alheit, 1993; Alheit; Hoernig, 1989) que, como uma paisagem, se constitui por diferentes camadas e regiões dispostas em patamares próximos ou distantes e que se transforma de tempos em tempos (precisamente por meio da aprendizagem). Nos nossos comportamentos cotidianos (e também nas situações explícitas de aprendizagem [Dewe, 1999]), quando nos concentramos de forma explícita sobre um "problema" - que representa apenas uma infima parte de nosso saber, de nossa experiência, de nossa ação -, nós recuperamos, a o mesmo tempo, uma grande parte de nosso saber (e de nosso não-saber) de maneira espontânea e não deliberada. Nós nos deslocamos de algum modo na paisagem de nosso saber biográfico, sem pensar de maneira consciente em cada um dos passos que fazemos em cada curva ou em cada indicação do caminho. Muitas vezes só invocamos elementos de nosso "plano de fundo" do saber biográfico quando damos um passo em falso, ao chegarmos a uma encruzilhada ou ao sentirmos que o chão se abre sob nossos pés. Temos, em princípio, a possibilidade de disponibilizarmos uma grande parte desse saber pré-reflexivo, de trabalhar de maneira explícita e, eventualmente, de transformar as estruturas da paisagem inteira. Tais processos reflexivos podem ser interpretados como momentos da formação de si (Alheit, 1993).

b) Dimensão da socialidade da aprendizagem biográfica: os processos reflexivos de aprendizagem não se desenvolvem, no entanto, apenas internamente ao indivíduo, mas dependem da comunicação e da interação com os outros, ou seja, da relação com um contexto social. A aprendizagem biográfica está ligada aos mundos-da-vida, os quais sob certas condições podem ser igualmente analisados como "ambientes" ou "meios" de aprendizagem. As noções de aprendizagem experiencial, aprendizagem no mundo-da-vida ou aprendizagem contextual dão conta desse aspecto do Lifelong Learning, conforme neles se vinculam a atenção conferida à associação e à configuração dos ambientes de aprendizagem 
(Dohmen, 1998). Pode-se, aliás, observar aqui duas tendências que devem ser avaliadas de maneira crítica a partir da análise biográfica dos processos de formação: por um lado uma interpretação "antiinstitucional" da aprendizagem ao longo da vida (Gieseke, 1997; Nuissi, 1997) que não considera que a biografia (e, portanto, a aprendizagem biográfica) e as instituições estejam ligadas entre si (ver, por exemplo, o estudo de Seitter, 1999) e, por outro lado, uma concepção tecnológica segundo a qual se poderia "fabricar", com quaisquer peças, ambientes de aprendizagem, que esquece que os "universos de aprendizagem" estão inscritos nos mundos-da-vida que se desenvolveram historicamente e que são o resultado de uma "produção" biográfica interativa: esses universos de aprendizagem são associados a espaços sociais determinados, eles revelam processos que podem ser acompanhados pedagogicamente, eles não podem ser fabricados ou comandados artificialmente.

c) Individualidade e significação pessoal da aprendizagem biográfica: se a aprendizagem biográfica está estruturada nas interações sociais, ela obedece, entretanto, a uma "lógica individual" que é o produto de uma estrutura biográfica particular da experiência adquirida. A estrutura biográfica não determina diretamente o processo de aprendizagem, pois é uma estrutura aberta que deve integrar novas experiências em relação com o mundo, os outros e si mesmo. Contudo, ela contribui essencialmente para fixar as modalidades segundo as quais se formam as novas experiências e que "se incorporam" nos processos de aprendizagem biográfica (Alheit; Dausien, 2000a). Os conceitos atuais de aprendizagem auto-organizada, autodefinida, autodirigida ou autodiretiva (Straka, 1997; Dohmen, 1998; Action concertée de formation continue, 1998) devem aqui ser objeto de um exame crítico (Report 39, 1997; Hoffmann; von Rein, 1998). Eles supõem, muitas vezes, um aprendente autônomo, que tem a maestria reflexiva e estratégica de seu próprio processo de formação.
Esse modelo de aprendente não considera a estratificação complexa da reflexividade biográfica. Os processos de formação biográfica têm seu próprio princípio de determinação, eles possibilitam experiências inesperadas e transformações surpreendentes que, muitas vezes, não foram previstas pelo próprio aprendente e só podem ser "compreendidas" posteriormente, mas que têm, entretanto, sua "direção" própria. Aqui os termos de "movimento de pesquisa" e de "orientação difusa para um objetivo" são mais apropriados do que o modelo cibernético de um "piloto automático" que se refere mais uma vez a condições institucionalizadas (por exemplo, de aquisição de saber). De um ponto de vista teórico, é no quadro conceitual da formação (Bildung), mais do que no de aprendizagem, que poderá se desenvolver uma compreensão biográfica da “autodeterminação". No nível das práticas de formação (inclusive das institucionais), para favorecer a elaboração biográfica dos processos de aprendizagem, é tão importante gerenciar os espaços de reflexão e de comunicação e mensurar os "possíveis" quanto desenvolver "instrumentos de pilotagem individuais".

\section{A formação como aprendizagem dos vínculos sociais}

Abordagem que esboçamos de uma teoria biográfica da formação nos permite retomar alguns pontos discutidos na Perspectiva l. Os processos de aprendizagem biográficos não devem ser compreendidos somente como operações de assimilação e de construção próprias para assegurar a organização reflexiva individual da experiência, do saber e do saberfazer. Eles também comportam o aspecto da constituição biográfica de redes e processos sociais, de saberes coletivos e de práticas coletivas: de um ponto de vista teórico, falar-seia, então, de "institucionalização" no sentido de Berger e Luckmann (1969), de constituição de um "capital social" ou de elaboração de práticas culturais (por exemplo, as que estão em 
jogo nos centros culturais e sociais, nas associações, nas iniciativas de bairro [Seitter, 1999; Field, 2000; Alheit; Dausien, 2000b]). Tanto quanto os processos individuais, o estabelecimento desses processos coletivos de formação só pode ser parcialmente explicitado e planejado. A partir das práticas biográficas dos indivíduos - que por definição escapam à ordenação -, nascem e se desenvolvem novos modelos e novas configurações de experiências que se abrem sobre caminhos "possíveis" de formação, sobre biografias possíveis de homens e de mulheres, sobre as formas "possíveis" de vínculo entre sexos e a interação entre culturas e gerações.

Do ponto de vista teórico, para dar conta dessa articulação do individual e do social, recorreremos uma vez mais ao princípio da biograficidade das experiências sociais. Se considerarmos a aprendizagem biográfica como a capacidade "autopoiética" de o sujeito organizar reflexivamente suas experiências e, assim fazendo - dar-se a si mesmo uma coerência pessoal e uma identidade, atribuir um sentido à história de sua vida, desenvolver capacidades de comunicação, de relação com o contexto social, de conduta da ação (Alheit, 1993; Alheit; Sausie 2000a) , torna-se possivel pensar a formação tanto como trabalho individual de gestão de identidade, quanto como constituição dos processos coletivos e dos vínculos sociais.

A perspectiva analítica aberta pela exploração da noção de aprendizagem biográfica ressalta claramente a pluralidade e a diversidade dos níveis que se encontram nos processos individuais de formação, assim como as contradições eventuais que resultam disso e que devem ser trabalhadas e superadas de forma pragmática pelos sujeitos: de um lado, o conteúdo programático da "aprendizagem ao longo da vida" faz emergir novos esquemas de espera e de significação que podem ser vividos subjetivamente tanto como uma sobrecarga de pressões sociais, quanto como uma nova abertura biográfica; por outro lado, os processos de aprendizagem biográficos e os projetos de vida associa- dos a eles são dependentes de estruturas institucionais e de contextos-de-vida, que podem favorecer ou impedir processos de formação individuais ou coletivos "autodefinidos". Enfim, do ponto de vista dos sujeitos, "aspiração" e "realidade" não estão mais em contradição: biograficamente, os dois níveis são igualmente "reais" e devem ser trabalhados individualmente e, ao longo de um processo de construção e de reconstrução biográfica estendido ao longo de toda a vida, ser integrados de forma sempre renovada na história de formação do sujeito. Para ter acesso a uma compreensão teórica mais precisa desses processos, para analisá-los empiricamente de maneira mais diferenciada e conceber, sobre essa base, abordagens em termos de práticas de formação, é necessário realizar outras pesquisas empíricas. A complexidade do problema exige, seguramente, um quadro conceitual de base - a teoria biográfica que esboçamos constitui uma aproximação - que seja nos moldes para responder na teoria e na prática ao conteúdo programático antinômico da aprendizagem ao longo da vida.

\section{Orientações da pesquisa no contexto da aprendizagem ao longo da vida}

A análise do fenômeno complexo que constitui "a aprendizagem ao longo da vida" conduz as ciências da educação a fazer a hipótese de uma mudança de paradigma, que pode ser expressa em muitos níveis:

- No nível macroestrutural da sociedade, em relação com uma nova política de formação que visa fundamentar um outro equilíbrio entre as formas do capital econômico, cultura e social (Alheit; Kreitz, 2000);

- No nível médio estrutural das instituições, na consideração de uma nova "reflexividade" das organizações que devem ser concebidas como "ambientes" e "agências" de recursos complexos de aprendizagem e de saber tanto quanto "administradores" e "mediadores" do 
saber dominante codificado (Field, 2000);

- No nível microestrutural dos indivíduos, considerando as operações de estabelecimento de elos e de perlaboração, cada vez mais complexas, efetuadas por atores concretos para responder às exigências sociais e midiáticas da pós-modernidade que requerem novas construções de sentido individuais e coletivas (Alheit, 1999).

De fato, sabemos ainda muito pouco sobre os equilíbrios sistêmicos entre o capital econômico e o capital social. Temos apenas um conhecimento limitado do "capital cerebral" que constitui o novo saber (Field, 2000) e de seus efeitos sobre os processos de aprendizagem em longo prazo. A comparação entre os diferentes tipos de sociedades pós-industriais - por exemplo, as diferenças significativas entre as políticas seguidas na Dinamarca ou na Grã Bretanha e as da Alemanha - para conduzir a uma "sociedade de aprendizagem", permitem contudo desenvolver, no nível internacional, perspectivas comparativas sistemáticas sobre as economias de formação.

Além disso, nossa informação sobre as condições institucionais da mudança do paradigma anunciado é aproximativa:

A quais forças de transformação as instituições de formação estão submetidas? Como elas reagem, quais perspectivas de solução lhes trazem? Qual é a amplitude das transformações (elas implicam, por exemplo, em reorganização parcial ou em redefinição completa do contrato de formação)? Como garantir, ao mesmo tempo, o espaço da liberdade de ação, a capacidade de inovação e a estabilidade das instituições? A quais concepções e a quais disposições recorrer para estabelecer e manter a qualidade da formação, o desenvolvimento das instituições e do pessoal? A partir de quais condições teóricas e empíricas justifica-se falar das instituições de formação como organizações abertas, elas mesmas, à aprendizagem? Qual quadro e quais estruturas favorecem seu desenvolvimento? (Memorando de pesquisa para a formação de adultos e a formação contínua, 2000, p. 13)

No percurso de vida da modernidade, descobrimos sem cessar novas "passagens de estatuto" e novas "fases de transição", marcadas por uma maior complexidade e por mais riscos para os sujeitos (Heinz, 2000b). Observamos nas biografias individuais a utilização de espantosas capacidades criativas de (re)construção (Alheit, 1994; Dausien, 1996; Kade; Seittler, 1996). No entanto, falta-nos ainda uma teoria elaborada e sistemática da aprendizagem biográfica:

Em quais culturas de aprendizagem e em quais configurações de modelos supra-individuais, de mentalidades e de meios se desenvolve a aprendizagem individual? Quais potenciais implícitos e quais tipos de aprendizagem se revelam nos meios sociais e nos grupos (por exemplo, no quadro da família e entre as gerações)? [...] Quais relações de interdependência pode-se constatar, por exemplo, entre, de um lado, as problemáticas e as soluções no nível coletivo e político e, de outro, a aprendizagem de indivíduos que a experimentam nos grupos, nas organizações, nas instituições? (Memorando de pesquisa para a formação dos adultos e a formação contínua, 2000, p. 5)

É a esse questionamento aberto que convida o "novo" conceito de Lifelong Learning. Seria extremamente desejável que se buscassem as respostas não apenas no discurso científico, mas também nas práticas de formação e no diálogo internacional. 


\section{Referências bibliográficas}

ALHEIT, P. Transitorische bildungsprozesse: das "biographische paradigma" in der weiterbildung. In: MADER, W. (Dir.) Weiterbildung und gesellschaft. grundlagen wissenschaftlicher und beruflicher praxis in der bundesrepublik deutschland. Bremen, 2ème éd., p. 343-418. 1993.

. Zivile kultur: verlust und wiederaneignung der moderne. Frankfurt a.M., New York. 1994.

On a contradictory way to the 'Learning Society': a critical approach. Studies in the Education of Adults. v. 31, n. 1 , p. 66-82. 1999.

ALHEIT, P.; DAUSIEN, B. Bildung als "biographische konstruktion"? Nichtintendierte lernprozesse in der organisierten erwachsenenbildung. Report. Literatur- und Forschungsreport Weiterbildung, v. 37, p. 33-45. 1996.

. Die biographische konstruktion der wirklichkeit: uberlegungen zur biographizität des sozialen. In: HOERNING, E. M. (Dir.) Biographische sozialisation. Stuttgart, p. 257-283. 2000a.

.'Biographicity' as a basic resource of lifelong learning. In: ALHEIT, P. et al., (Dir.). Lifelong learning inside and outside schools, v. 2. - Roskilde, p. 400-422. 2000b.

ALHEIT, P.; HOERNING, E. M. (Dir.) Biographisches wissen: beiträge zu einer theorie lebensgeschichtlicher erfahrung Frankfurt a. M. 1989.

ALHEIT, P.; KAMMLER, E. (Dir.) Lifelong learning and its impact on social and regional development.. Bremen. 1998.

ALHEIT, P.; KREITZ, R. 'Social Capital', 'Education' and the 'Wider Benefits of Learning': review of 'models' and qualitative research outcomes. Expertise pours le Centre of Education de l'University of London et le Department for Education and Employment du gouvernement anglais. Göttingen; London (manuscript non publié). 2000.

ALHEIT, P.; PIENING, D. Assessment of prior experiential learning as a key to lifelong learning: evaluating european practices. Bremen. 1999.

ARTHUR, M. B.; INKSON, K.; PRINGLE, J. K. The New Careers: individual action and economic change. London. 1999.

BECK, U. Jenseits von stand und klasse? Soziale ungleichheiten, gesellschaftliche Individualisierungsprozesse und die entstehung neuer sozialer funktionen und identitäten. In: KRECKEL, R. (Dir.) Soziale ungleichheiten: soziale welt. Sonderband 2. Göttingen, p. 35-74. 1983.

Risikogesellschaft: auf dem weg in eine andere moderne. Frankfurt a.M. 1986.

BECK, U.; GIDDENS, A.; LASH, S. Reflexive modernisierung: eine kontroverse. Frankfurt a.M. 1996.

BENTLEY, T. Learning beyond the classroom: education for a changing world. London. 1998.

BERGER, P.; LUCKMANN, T. Die gesellschaftliche konstruktion der wirklichkeit: eine theorie der wissenssoziologie. Frankfurt a.M. 1969.

BORN, C. Erstausbildung und weiblicher lebenslauf: was (nicht nur) junge frauen bezüglich der berufswahl wissen sollten. In: HEINZ, W. (Dir.) Übergänge: individualisierung, flexibilisierung und institutionalisierung des lebenslaufs. Zeitschrift für Soziologie der Erziehung und Sozialisation. Weinheim, p. 50-65. 2000.

BOURDIEU, P. Die feinen Unterschiede: kritik der gesellschaftlichen urteilskraft. Frankfurt a.M. 1987.

COMMISSION OF THE EUROPEAN COMMUNITIES. Competitiveness, employment, growth. Luxembourg. 1994.

Teaching and learning: towards the learning society. Luxembourg. 1995.

A memorandum on lifelong learning. Lissabon. 2000. 
DAUSIEN, B. Biographie und geschlecht: zur biographischen konstruktion sozialer wirklichkeit in frauenlebensgeschichten. Bremen. 1996.

Lebensbegleitendes lernen in den biographien von frauen: ein biographietheoretisches bildungskonzept. In: GIESEKE, W.

(Hrsg.) Handbuch zur Frauenbildung. Opladen (à paraître en 2005). 2001.

DELORS, J. Learning: the treasure within. Report to UNESCO of the International Commission on Education for the Twenty-first Century. Paris. 1996.

DELORY-MOMBERGER, C. Les histoires de vie: de l'invention de soi au projet de formation. Paris: Anthropos. [2000] 2004.

DEPARTMENT FOR EDUCATION AND EMPLOYMENT. The learning age: a renaissance for a new britain. Sheffield. 1998.

DEWE, B. Lernen zwischen vergewisserung und ungewißheit: reflexives handeln in der erwachsenenbildung. Opladen. 1999.

DOHMEN, G. Das lebenslange lernen: leitlinien einer modernen bildungspolitik. Bonn. 1996.

Zur zukunft der weiterbildung in europa: lebenslanges lernen für alle in veränderten lernumwelten. Bonn. 1998.

DOMINICE, P. L'Histoire de vie comme processus de formation. Paris: L'Harmattan. 1990.

FAURE, E. Learning to be: the world of education today and tomorrow. Paris. 1972.

FIELD, J. Lifelong learning and the new educational order. Stoke on Trent, UK. 2000.

GERLACH, C. Lebenslanges lernen: konzepte und entwicklungen 1972 bis 1997. Köln. 2000.

GIDDENS, A. Consequences of modernity. Cambridge. 1990.

The third way: the renewal of social democracy. Cambridge. 1998.

GIESEKE, W. Lebenslanges lernen aus der perspektive der geschlechterdifferenz. Report Literatur und Forschungsreport Weiterbildung, v. 39, p. 79-87. 1997.

GROUP OF EIGHT. KöIn Charter: aims and ambitions for lifelong learning. Köln. 1999.

HALL, P. Social capital in britain. British Journal of Political Science, v. 29, n. 3, p. 417-461. 1999.

HEINZ, W. Editorial: strukturbezogene biographie und lebenslaufforschung: der sfb 186. Statuspassagen und Risikolagen im Lebensverlauf. In: ___ (Dir.) Übergänge: Individualisierung, Flexibilisierung und Institutionalisierung des Lebenslaufs. 3. Beiheft 2000 der ZSE. Zeitschrift für Soziologie der Erziehung und Sozialisation. Weinheim, p. 4-8. 2000a.

(Dir.) Übergänge. Individualisierung, Flexibilisierung und Institutionalisierung des Lebenslaufs. 3. Beiheft 2000 der ZSE. Zeitschrift für Soziologie der Erziehung und Sozialisation. Weinheim. 2000b.

HOFFMANN, N.; von REIN, A. (Hrsg.) Selbstorganisiertes lernen in (berufs) biographischer reflexion. Frankfurt a. M. 1998.

KADE, S. Altersbildung: lebenssituation und lernbedarf, ziele und konzepte, v. 2, Frankfurt a. M. 1994a.

(Dir.) Individualisierung und älterwerden. Bad Heilbrunn. 1994b.

Riskante biographien und die risiken lebenslangen lernens. Report: Literatur und Forschungsreport Weiterbildung, v. 39, p. 112-124. 1997.

KADE, J.; SEITTER, W. Lebenslanges lernen: mögliche bildungswelten, erwachsenenbildung, biographie und alltag. Opladen. 1996.

KÖRBER, K. Zur antinomie von politisch-kultureller und arbeitsbezogener bildung in der erwachsenenbildung. In: Bildung in der Arbeitsgesellschaft. Zum Spannungsverhältnis von Arbeit und Bildung heute. Dokumentation des 10. Bremer Wissenschaftsforums vom 11. bis 13. Oktober, 1988. Bremen, p. 126-151. 1989. 
KOHLI, M. Die institutionalisierung des lebenslaufs: historische befunde und theoretische argumente. Kölner Zeitschrift für Soziologie und Sozialpsychologie, v. 37, p. 1-29. 1985.

Institutionalisierung und Individualisierung der Erwerbsbiographie. Aktuelle Veränderungstendenzen und ihre Folgen. In: BROCK, D. U. A. (Dir.) Subjektivität im gesellschaftlichen wandel: umbrüche im beruflichen sozialisationsprozeß. München, p. 249-278. 1989.

LONGWORTH, N.; DAVIES, W. K. Lifelong learning: new vision, new implications, new roles for people, organizations, nations and communities in the 21stcentury. London. 1999.

MADER, W. (Dir.) Altwerden in einer alternden gesellschaft: kontinuität und krisen in biographischen verläufen. Opladen. 1995. . Lebenslanges Lernen oder die lebenslange Wirksamkeit von emotionalen Orientierungssystemen. Report. Literatur und Forschungsreport Weiterbildung, v. 39, p. 88-100. 1997.

MAROTZKI, W. Entwurf einer strukturalen bildungstheorie: biographietheoretische auslegung von bildungsprozessen in hochkomplexen gesellschaften. Weinheim. 1990.

MERRILL, B. Gender, change and identity: mature women students in universities. Aldershot. 1999.

NASSEHI, A. Die form der biographie: theoretische überlegungen zur biographieforschung in methodologischer absicht. BIOS: Zeitschrift für Biographieforschung und Oral History, v. 7, n. 1, p. 46-63. 1994.

NOLDA, S. (Dir.) Erwachsenenbildung in der wissensgesellschaft. Bad Heilbrunn. 1996.

NUISSL, E. Institutionen im lebenslangen Lernen. Report. Literatur- und Forschungsreport Weiterbildung, v. 39, p. 41-49. 1997.

OECD. Lifelong learning for all: meeting of the education commettee at ministerial level. v. 16/17. Paris. 1996.

. Literacy skills for the knowledge society: further results of the international adult literacy survey. Paris. 1997a.

What works in innovation in education: combatting exclusion through adult learning. Paris. 1997b.

OECD; CERI Recurrent education: a strategy for lifelong learning: a clarifying report. Paris. 1973.

PUTNAM, R. D. Gesellschaft und gemeinsinn: sozialkapital im internationalen vergleich. Gütersloh. 2001.

RABE-KLEBERG, U. Verantwortlichkeit und macht: ein beitrag zum verhältnis von geschlecht und beruf angesichts der krise traditioneller frauenberufe. Bielefeld. 1993a.

Bildungsbiographien - oder: Kann Hans noch lernen, was Hänschen versäumt hat? In: MEIER, A.; RABE-KLEBERG, U. (Hrsg.) Weiterbildung, lebenslauf, sozialer wandel. Neuwied, p. 167-182. 1993b.

RAHMSTORF, G. Wissensgesellschaft. Nachricht Nr. 00079 im Archiv der Mailingliste wiss-org (source Internet). 1999.

REPORT 39 Report: Literatur- und Forschungsreport Weiterbildung, v. 39. 1997.

SCHLÜTER, A. Bildungsmobilität: studien zur individualisierung von arbeitertöchtern in der moderne. Weinheim. 1993.

SCHLÜTER, A.; FILD, J. Bildungserfolge: eine analyse der wahrnehmungs- und deutungsmuster und der mechanismen für mobilität in bildungsbiographien. Opladen. 1999.

SCHULZE, T. Lebenslauf und Lebensgeschichte. In: BAACKE, D.; SCHULZE, T. (Dir.) Aus geschichten lernen: zur einübung pädagogischen verstehens. Weinheim, p. 174-226. 1993a.

.Zum ersten mal und immer wieder neu: skizzen zu einem phänomenologischen lernbegriff. In: BAUERSFELD, H.; BROMME, R. (Dir.) Bildung und aufklärung. Münster, p. 241-269. 1993b. 
SEITTER, W. Riskante übergänge in der moderne: vereinskulturen, bildungsbiographien, migranten. Opladen. 1999.

SIMONS, P. R. J. Theories and principles of learning to learn. In: TUJINMAN, A.; van der KAMP, M. (Dir.) Learning across the lifespan: theories, research, policies. Oxford, p. 173-188. 1992.

SMITH, R. M. Implementing the learning to learn concept. In: TUJINMAN, A.; van der KAMP, M. (Dir.) Learning across the lifespan: theories, research, policies. Oxford, p. 173-188. 1992.

STEHR, N. Erwerbsarbeit in der wissensgesellschaft oder informationstechnologien, wissen und der arbeitsmarkt. Vancouver (source Internet). 2000.

STRAKA, G. A. Selbstgesteuertes lernen in der Arbeitswelt. Report: Literatur- und Forschungsreport Weiterbildung, v. 39, p. 146-154. 1997.

TAVISTOCK INSTITUTE A review of thirty new deal partnerships. Research and Development Report ESR 32, Employment Service. Sheffield. 1999.

TUCKETT, A.; SARGANT, N. Making time: the NIACE survey on adult participation in learning 1999. Leicester. 1999.

VESTER, M. U. A. Soziale milieus im gesellschaftlichen strukturwandel: zwischen integration und ausgrenzung. Köln. 1993.

WINGENS, M. Wissensgesellschaft und industrialisierung der wissenschaft. Wiesbaden. 1998. 